\title{
Erratum to: The influences of filament temperature on the structure of boron nitride films and its tribological characterization for microforming die application
}

Yong Jin ${ }^{1, *}$, Shigeo Yasuhara ${ }^{2}$, Tetsuhide Shimizu ${ }^{1}$, and Ming Yang ${ }^{1}$

1 Graduate School of System Design, Tokyo Metropolitan University, Hino 191-0065, Japan

2 Japan Advanced Chemicals, 3131-4 Tana, Chuo-ku, Segamihara-shi, Kanagawa 252-0244, Japan

Manufacturing Rev. 2015, 2, 4, DOI: 10.1051/mfreview/2015007

Published online: 25 March 2015

We realized that due to an unfortunate mistake Figure 2 was wrong in page 3 of the paper. Following the "Erratum", we publish the article with the correct version of Figure 2. We apologize for the inconvenience that this mistake may have caused. 


\title{
The influences of filament temperature on the structure of boron nitride films and its tribological characterization for microforming die application
}

\author{
Yong Jin ${ }^{1, *}$, Shigeo Yasuhara $^{2}$, Tetsuhide Shimizu ${ }^{1}$, and Ming Yang ${ }^{1}$ \\ 1 Graduate School of System Design, Tokyo Metropolitan University, Hino 191-0065, Japan \\ 2 Japan Advanced Chemicals, 3131-4 Tana, Chuo-ku, Segamihara-shi, Kanagawa 252-0244, Japan
}

Received 7 January 2015 / Accepted 24 February 2015

\begin{abstract}
Boron nitride film was deposited on $\left\langle\begin{array}{lll}1 & 0 & 0\end{array}\right\rangle$-oriented silicon substrate by hot filament assisted chemical vapor deposition. The $\mathrm{B}\left[\mathrm{N}\left(\mathrm{CH}_{3}\right)_{2}\right]_{3}$ (Tris(dimetylamino)borane, TDMAB) was used as the single source precursor both for boron and nitride, and ammonia gas was used as the extra source to increase the $\mathrm{N}$ concentration in the films. Elemental composition of the films deposited under different filament temperatures were measured by energy dispersive X-ray (EDX) analysis, and the structure of the films were measured by X-ray diffraction (XRD) and Fourier transform infrared spectroscopy (FT-IR). The boron nitride films deposited under lower filament temperature was amorphous, while BN films contain hexagonal structure were deposited at higher filament temperature. To verify whether the films can be applied for microforming die, ball on disk test was carried out using pure titanium ball as the counterpart to investigate the interfacial behavior between the films and pure titanium. The results show that the reaction between the films and pure titanium was low as there was no titanium adhesion on the wear track when the film was remained.
\end{abstract}

Key words: Filament temperature, Boron nitride, Structure, Tribological, Microforming

\section{Introduction}

Because of the similar crystal structure and properties as diamond, cubic boron nitride $(\mathrm{cBN})$ has gained more and more attention from the last decades. And some properties of $\mathrm{cBN}$ are superior to diamond, like high temperature oxidation resistance and chemical inertness to ferrous alloys. Due to these properties, cBN has a wide application field as cutting tools and wear resistant coatings used in metal forming [1].

Various techniques were used to deposit cBN films, such as physical vapor deposition (PVD) and chemical vapor deposition (CVD) methods. These methods like ion-beam assisted deposition [2], RF sputtering [3] and ion-assisted CVD [4] have been succeeded in depositing nano-cBN films. However, these methods involve energetic ion bombardment, which causes the high compressive stress in the films. This internal stress leads the films cracking and delamination when the films thickness exceeds to several hundreds of nanometers, and it is

*e-mail: jinyonghit@gmail.com difficult to deposit thick cBN films over $1 \mu \mathrm{m}$ without delamination.

Compared with the PVD methods or plasma assisted CVD methods with high stress in the films, a simple chemical way for deposition of thick cBN films would be of high interest for industrial applications because of reducing the stress in the film. Weissenbacher and Haubner [5] used hot filament CVD to decompose the Triethylborazine $\left(\mathrm{C}_{6} \mathrm{H}_{18} \mathrm{~B}_{3} \mathrm{~N}_{3}\right)$ source on various substrates, and obtained the $\mathrm{B}, \mathrm{C}$ and $\mathrm{N}$ containing layers under different deposition conditions. Dumont et al. [6] used the Tris(dimethylamino)borane (TDMAB) as the single source precursor, and deposited the BN films on $\mathrm{Si}$ substrate under different deposition temperature. However, some difficulties appear in the deposition of cBN film by CVD without energetic plasma bombardment, and there has no available thermodynamic data as well as the exact transition temperature between $\mathrm{hBN}$ and $\mathrm{cBN}$.

In this work, BN films were deposited by hot filament assisted CVD method, and the TDMAB gas was used as the single source precursor which was decomposed and activated by the hot filament. The influence of different filament 


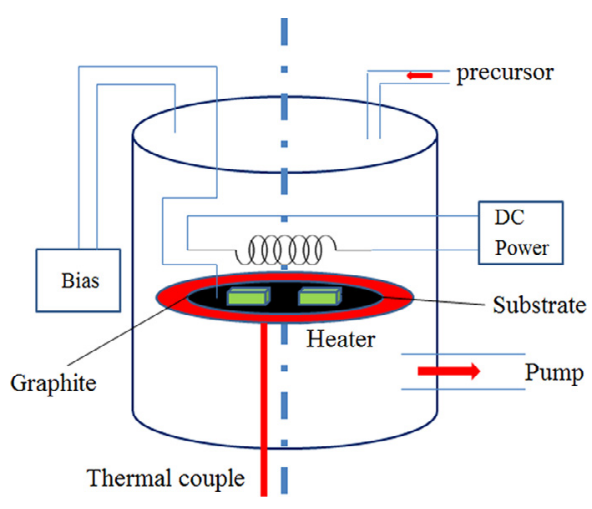

Figure 1. Schematic diagram of the deposition unit.

temperature on the structure of $\mathrm{BN}$ film was studied. On the other hand, in order to investigate the possibility of the films applied to microforming die for forming pure titanium, the tribological properties and interfacial behavior between the films and pure titanium were investigated by using ball on disk test.

\section{Experiment}

BN films were deposited on $\left\langle\begin{array}{llll}1 & 0 & 0\end{array}\right\rangle$-oriented silicon substrate by hot filament assisted CVD. Figure 1 shows the schematic diagram of the experimental set up which was designed by Japan Advanced Chemicals Ltd. The $\mathrm{B}\left[\mathrm{N}\left(\mathrm{CH}_{3}\right)_{2}\right]_{3}$ (TDMAB) gas was chose as the single source precursor since its nontoxic properties and the fixed ratio of boron and nitride. BN films were deposited under different filament temperatures which were controlled by a direct-current supply power. Since the $\mathrm{N}$ content in the films were much lower than the B content, ammonia gas was used as the extra gas to increases the $\mathrm{N}$ content in the films. Si substrates were cleaned by acetone and ethanol in an ultrasonic bath before deposition, and put on a graphite substrate which was heated to $700{ }^{\circ} \mathrm{C}$ by a $\mathrm{SiC}$ ceramic heater. The detail deposition conditions are summarized in Table 1.

All the films obtained were analyzed by energy dispersive X-ray (EDX) analysis to estimate the elemental compositions. $\mathrm{X}$-ray diffraction (XRD) and Fourier transform infrared spectroscopy (FT-IR) were used to identify the structure of the films. The thickness of the film was measured by atomic force microscopy (AFM). The interfacial behavior and friction coefficient of the films were measured by ball-on-disk (BOD) tribometer. A constant normal force of $1 \mathrm{~N}$ was applied for all the tests, and the force corresponds to an initial Hertzian mean contact pressure of about $343 \mathrm{MPa}$ [7]. The details of BOD test conditions are summarized in Table 2.

\section{Results and discussion}

\subsection{Measurement of the BN films}

\subsubsection{Elemental composition and structure of the films}

Table 3 shows the elemental composition of the films deposited with different filament temperature measured by
Table 1. BN films deposition conditions.

\begin{tabular}{lc}
\hline Substrate & $p$-type Si $\left(\begin{array}{ll}1 & 0\end{array}\right)$ \\
\hline Working pressure $(\mathrm{Pa})$ & 40 \\
Substrate temperature $\left({ }^{\circ} \mathrm{C}\right)$ & 700 \\
Carrier gas flow rate $(\mathrm{sccm})$ & 30 \\
Ammonia gas flow rate $(\mathrm{sccm})$ & 300 \\
Bias voltage $(\mathrm{V})$ & 100 \\
Filament temperature $\left({ }^{\circ} \mathrm{C}\right)$ & $1500,1800,2000$ \\
Filament distance $(\mathrm{mm})$ & 10 \\
Deposition time $(\mathrm{min})$ & 30 \\
\hline
\end{tabular}

Table 2. Ball-on-disk test conditions.

\begin{tabular}{lc}
\hline Ball material & Pure titanium \\
\hline Ball diameter & $6 \mathrm{~mm}$ \\
Rotation speed & $50 \mathrm{rpm}$ \\
Rotation radius & $3 \mathrm{~mm}$ \\
Loading & $1 \mathrm{~N}$ \\
Ending condition & $100 \mathrm{laps}$ \\
\hline
\end{tabular}

Table 3. Element compositions of the films deposited under different filament temperatures.

\begin{tabular}{|c|c|c|c|c|c|c|}
\hline \multicolumn{2}{|c|}{ Samples Filament temperature $\left({ }^{\circ} \mathrm{C}\right)$} & \multicolumn{5}{|c|}{ Element compositions (at.\%) } \\
\hline & & B & $\mathrm{N}$ & $\mathrm{C}$ & $\mathrm{O}$ & $\mathrm{Si}$ \\
\hline No. 1 & 1500 & 52.50 & 14.96 & 13.46 & 2.16 & 16.93 \\
\hline No. 2 & 1800 & 61.50 & 22.24 & 0 & 0.57 & 15.67 \\
\hline No. 3 & 2000 & 61.84 & 25.66 & 0 & 0.77 & 11.73 \\
\hline
\end{tabular}

EDX analysis. The elemental composition of the films was influenced by the different filament temperature. With increasing the filament temperature, the $\mathrm{N}$ concentration in the films increased. There is no $\mathrm{C}$ contains in the films when the filament temperature increased to $1800{ }^{\circ} \mathrm{C}$. The thicknesses of the films deposited under different filament temperatures were $133 \mathrm{~nm}, 265 \mathrm{~nm}$ and $316 \mathrm{~nm}$, respectively. This suggested that the higher temperature of filament makes the precursor being decomposed completely, and the deposition rate of the films were increased with increasing the filament temperature.

The structures of the films were analyzed by FT-IR and XRD analysis. The FT-IR analysis is a most important and widely used tool for characterizing $\mathrm{BN}$ films, for $\mathrm{hBN}$, the two IR-active phonons have TO frequencies at about $\sim 780$ and $\sim 1370 \mathrm{~cm}^{-1}$, respectively. The $1370 \mathrm{~cm}^{-1}$ mode is a stretching of the B-N bond within the basal plane, and the $780 \mathrm{~cm}^{-1}$ mode is a bending of the B-N-B bond between the basal planes [1]. Figure 2 shows the FT-IR results of the films as shown in Table 3. The FT-IR spectra of the films deposited with different filament temperature were different. At the lower filament temperature, no clear peak was observed, the spectra looks smooth and with some broad peaks. When the filament temperature increased to $1800{ }^{\circ} \mathrm{C}$, two peaks with wide wavenumber were detected. The intensity of the peaks increase and become narrow when the filament temperature increased to $2000{ }^{\circ} \mathrm{C}$. These two peaks correspond well to the peaks of $\mathrm{hBN}$ in the FT-IR spectra [1]. It indicated that 
(a)

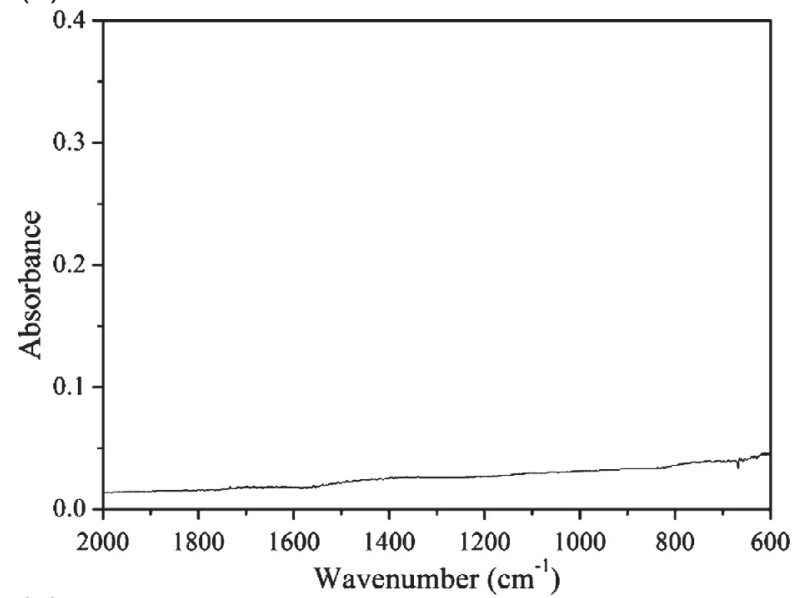

(b)

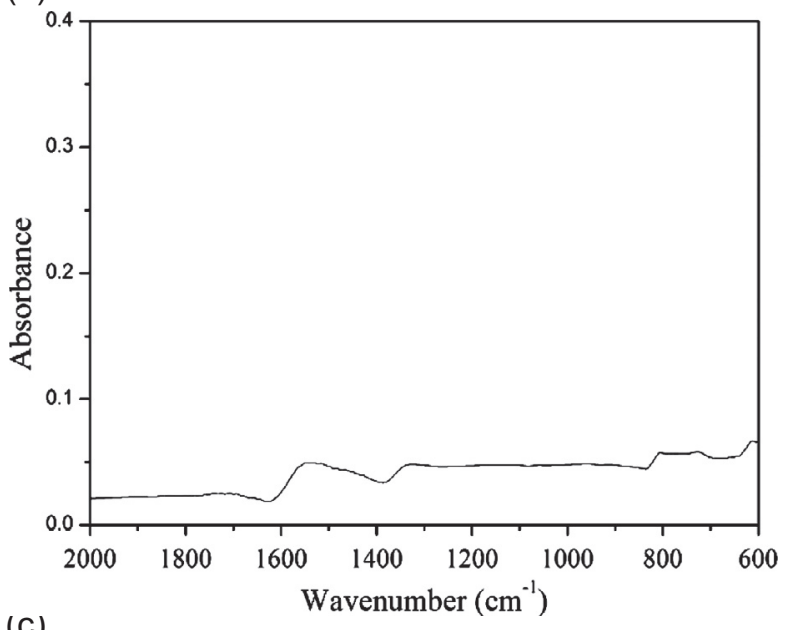

(C)

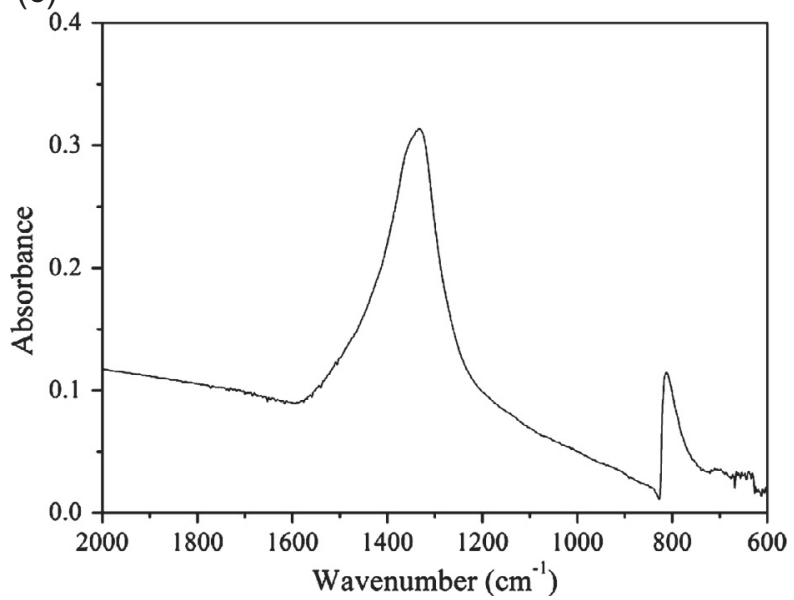

Figure 2. FT-IR results of the films deposited under different filament temperatures: (a) $1500{ }^{\circ} \mathrm{C}$, (b) $1800{ }^{\circ} \mathrm{C}$, (c) $2000{ }^{\circ} \mathrm{C}$.

the film deposited under lower filament temperature has disordered structures or amorphous, and hBN films could be deposited under higher filament temperatures.

Figure 3 shows the XRD results of the films as shown in Table 3. It can be found that no peak was detected in the XRD spectra when the film was deposited under lower filament temperature. As the filament temperature increased to

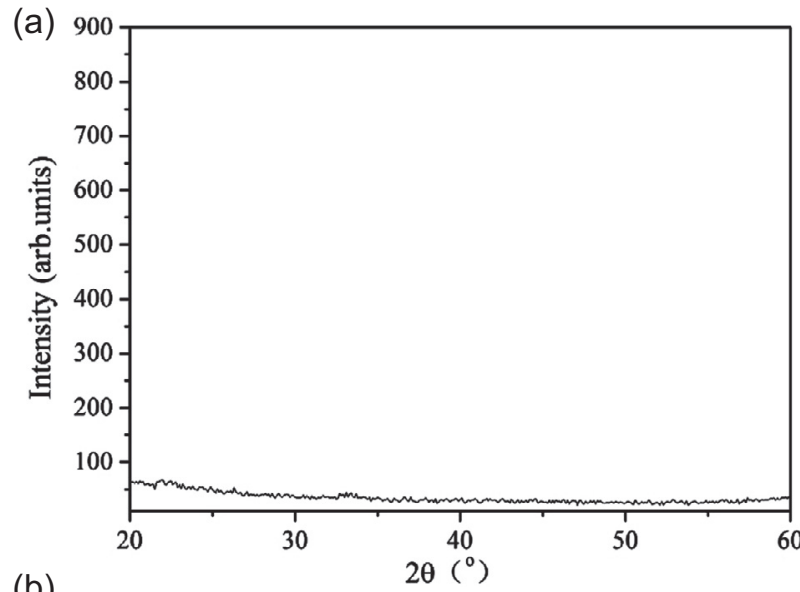

(b)

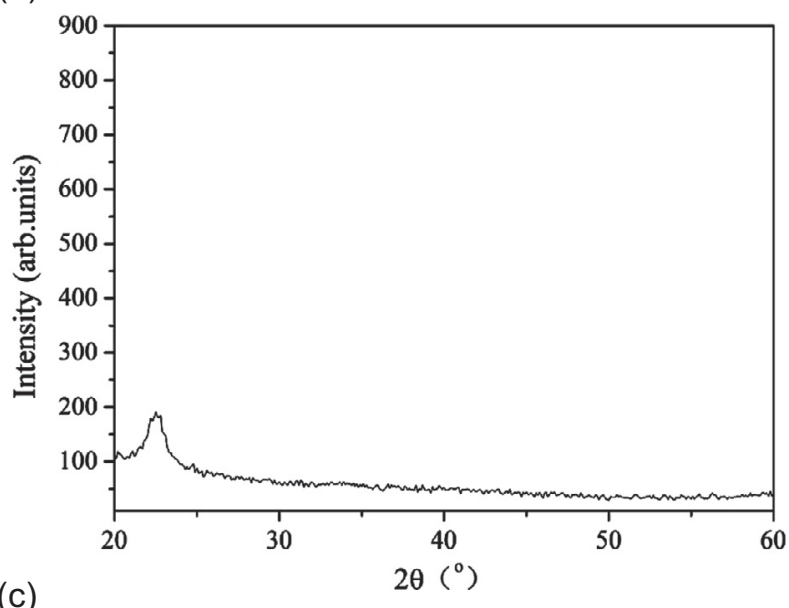

(c)

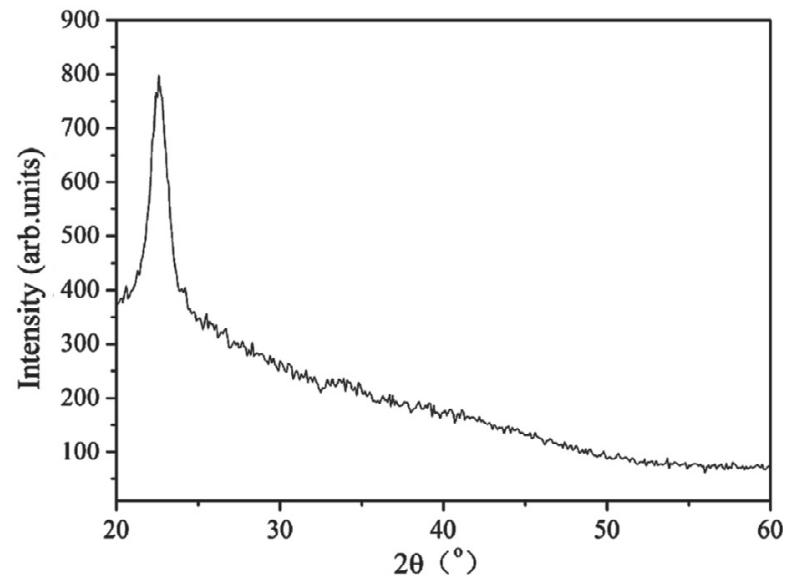

Figure 3. XRD results of the films deposited with different filament temperatures: (a) $1500{ }^{\circ} \mathrm{C}$, (b) $1800{ }^{\circ} \mathrm{C}$, (c) $2000{ }^{\circ} \mathrm{C}$.

$1800{ }^{\circ} \mathrm{C}$, a peak around $23^{\circ}$ was observed, and the intensity of this peak increases as the filament temperature further increased. It indicated that the crystallization degree of the films was increased with increasing the filament temperature. However, the $\left(\begin{array}{lll}0 & 0 & 2\end{array}\right)$ diffraction peak position for $\mathrm{hBN}$ is reported at $2 \theta=26.8^{\circ}$ [8], the peak shift to the small angle may be caused by the rich B content in the film. The excessive $\mathrm{B}$ atom may incorporate into the structure, and causes the lattice constant increase. According to Bragg's low [9], the angle 
would be decreased if the lattice constant increase. This needs further investigation in the future.

From the FT-IR and XRD measurements, it suggested that the hBN films were deposited at higher filament temperature, and the crystallization degree of the BN films become better as the filament temperature increased. In order to investigate whether the hBN films can be applied for microforming die for forming pure titanium, the BOD tests were carried out to investigate the tribological properties and interfacial behavior between the $\mathrm{BN}$ films and pure titanium.

\subsubsection{Tribological properties and interfacial behavior of the film}

Figure 4 shows the friction coefficient of the films deposited with different filament temperature. From these results, it can be observed that the films deposited at lower filament temperatures show the higher and big vibration friction coefficient than the film deposited at higher filament temperature. The friction coefficient of the film deposited at higher filament temperature was different compare with the films deposited at lower filament temperature. At the initial stage of the BOD test, the friction coefficient is low and smooth, while it was increased rapidly and vibrated after 20 laps. After BOD test, many wear debris were found on the edge of the wear track. As the hBN film was very soft and it was easily to be removed, the wear debris on the wear track may increase the friction coefficient, and the friction coefficient increased after the film was worn out.

As the life time of the film was too short due to the thin thickness, in order to investigate the wear properties and interfacial behavior of the film sliding against with pure titanium, the thick $\mathrm{hBN}$ film was needed. Figure 5 shows the surface morphology of the films deposited for 120 min with the filament temperature at $2000{ }^{\circ} \mathrm{C}$, the other deposition conditions were the same as before. The thickness of the film is around $2 \mu \mathrm{m}$ measured by AFM. From the SEM image of the hBN film, it was found that the film has regular structures with the size around $1 \mu \mathrm{m}$.

Figure 6 shows the friction coefficient of the film measured by BOD test under the same testing condition except the sliding lap increased from 100 to 800 . The friction coefficient of the film shows the same tendency as the film with thin thickness. The friction coefficient of the film was low and stable at the initial stage, then it increases as the sliding laps increased. In order to study the interfacial behavior between the film and pure titanium, the elemental composition of the wear track on the film was measured during the initial stage and after the BOD test.

Figure 7 shows the surface morphology and EDX results of the film after 50 and 800 laps. The results show that there was no titanium adhesion on the wear track after 50 laps, when the sliding lap increased to 800 laps, the titanium was detected and adhesion on the wear track. It was considered that the titanium was adhesion on the film only when the film was worn out. In other words, if $\mathrm{hBN}$ film was remained, the titanium would not adhesion on the film.

From the BOD test, it was found that the hBN film has low friction coefficient and low reaction with pure titanium, it
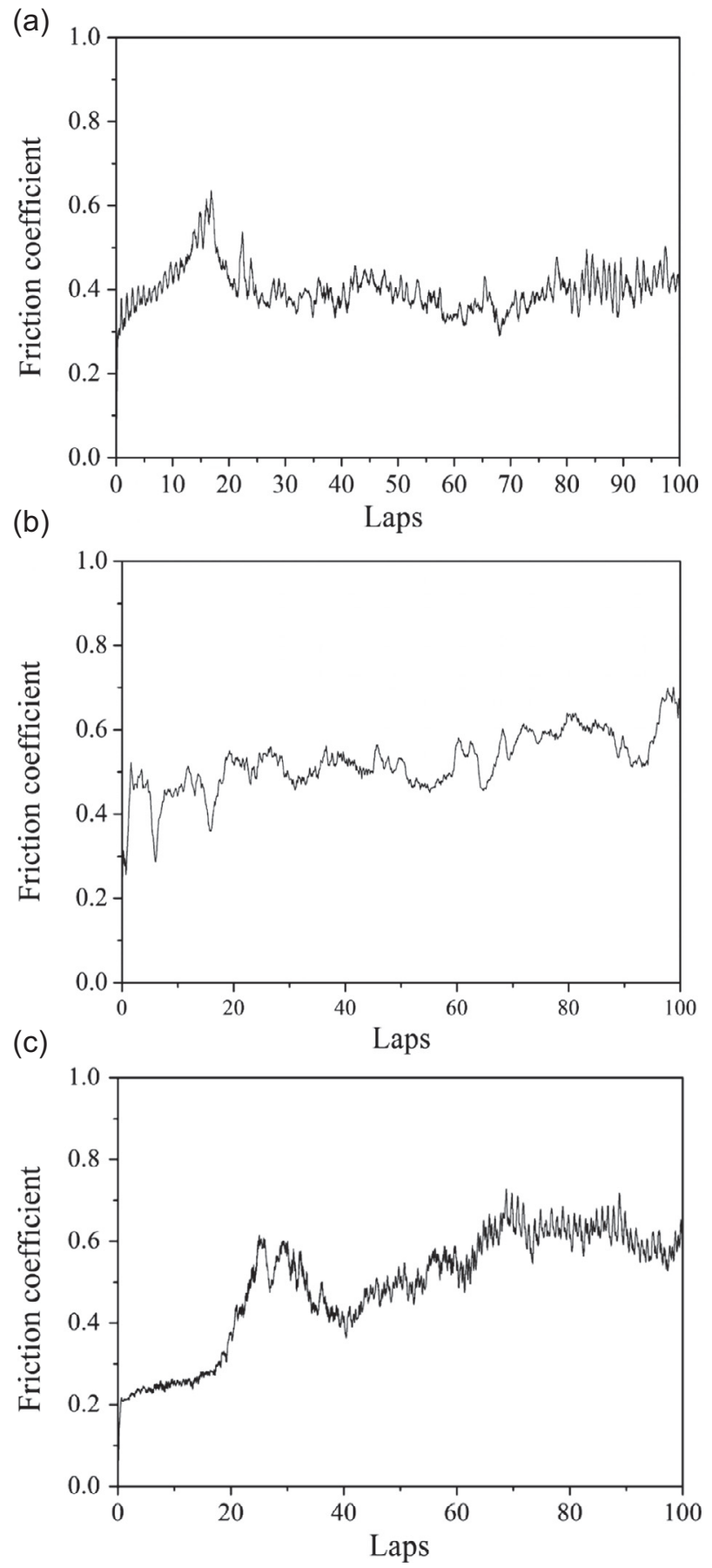

Figure 4. Friction coefficient of the films with different filament temperature: (a) $1500{ }^{\circ} \mathrm{C}$, (b) $1800{ }^{\circ} \mathrm{C}$, (c) $2000{ }^{\circ} \mathrm{C}$.

could be applied to the microforming die for forming pure titanium. However, the adhesion strength or the wear resistance of the film was low, it was easily to be worn out during the BOD test.

\subsection{Discussion}

BN films contain hexagonal structure could be deposited at higher filament temperature by the filament assisted chemical 


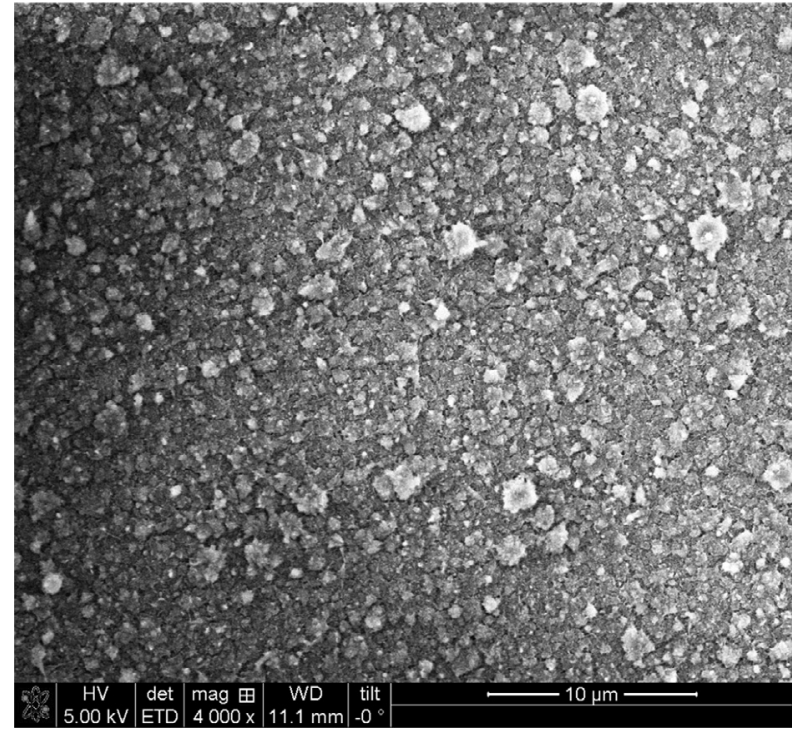

Figure 5. SEM image of the hBN film deposited for $120 \mathrm{~min}$.

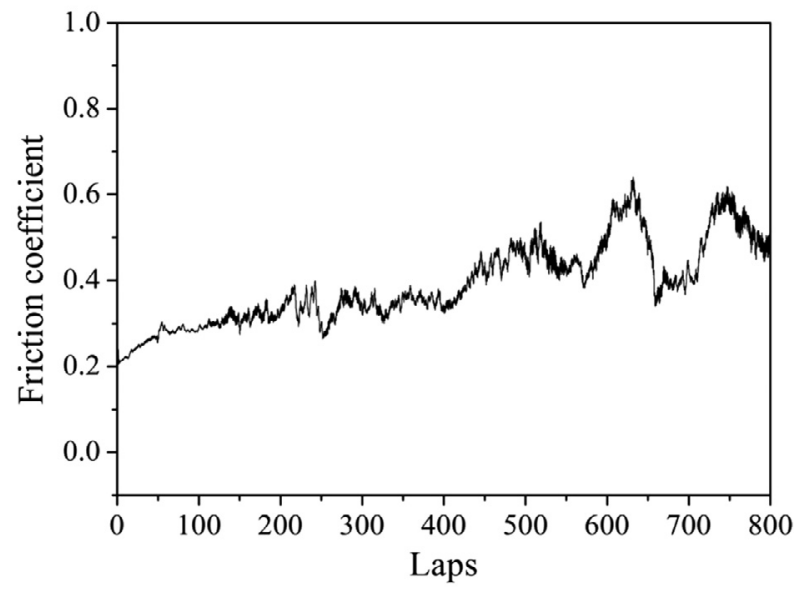

Figure 6. Friction coefficient of the $\mathrm{hBN}$ film deposited for $120 \mathrm{~min}$

vapor deposition, the higher temperature of filament makes the higher electron energy and lead to the hexagonal structure of $\mathrm{BN}$ formation. As there was no energetic ion/plasma bombardment during the deposition process, the internal stress in the films was much lower than the films deposited by PVD or PECVD process. The energy for $\mathrm{cBN}$ nucleation is higher than the energy for $\mathrm{hBN}$ film formation, if the electron energy from filament can be higher enough for $\mathrm{cBN}$ nucleation, it was possible to deposit the thick cBN film with lower internal stress by the filament assisted CVD process.

For microforming die application, the coating system should has low friciton coefficient, low wear rate, high adhesion strength on the tool and low reaction with forming (a)
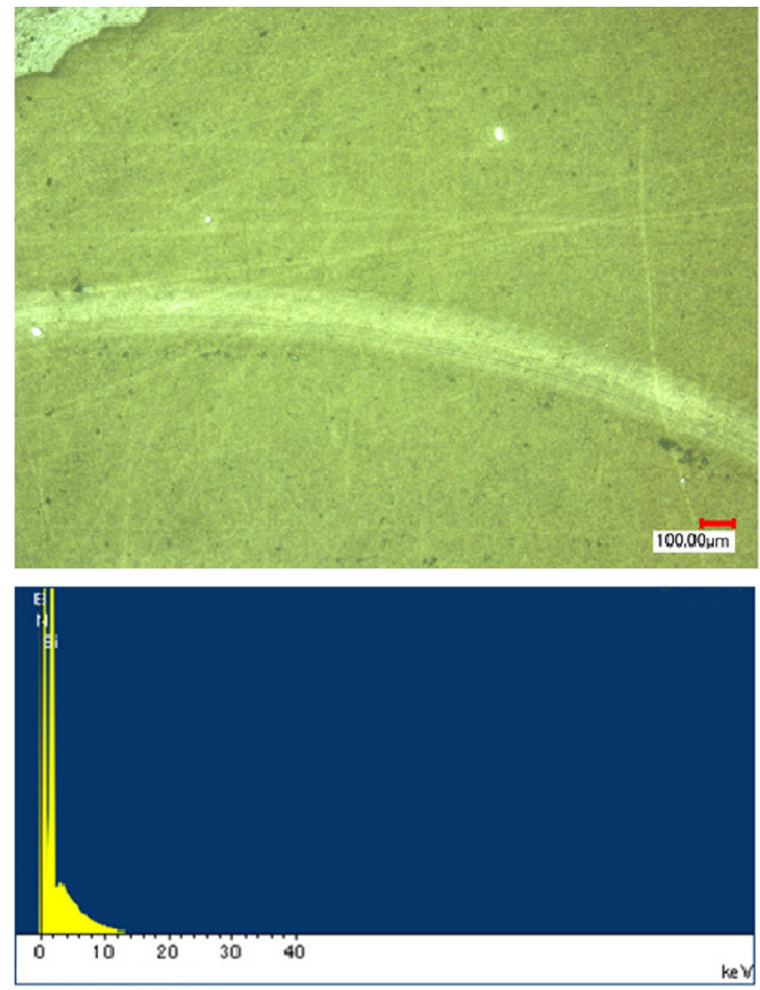

(b)
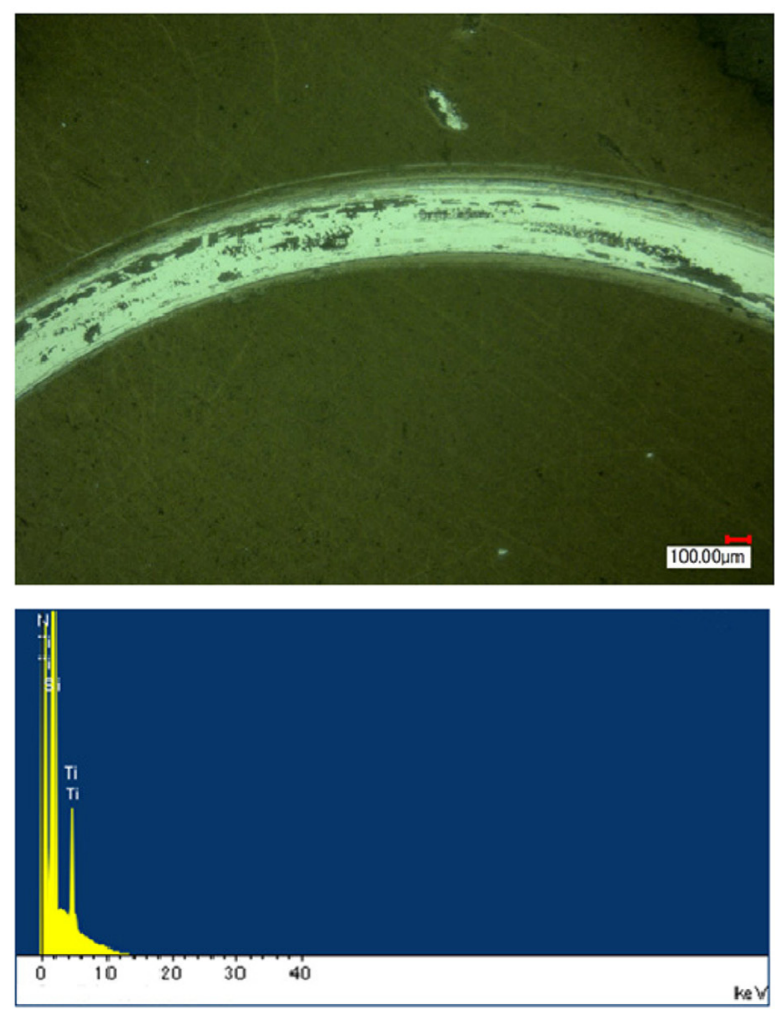

Figure 7. EDX measurement of the wear track on the film after BOD test: (a) wear track of the film after 50 laps, (b) wear track of the film after 800 laps. 
materials. The BOD test shows that the hBN films has low friction coefficient and chemical inertness to pure titanium, it could be used as the coatings for microforming tool to prevent pure titanium sticking on the tool surface. However, the wear rate of the hBN films was high and it was easily to be worn out. In order to apply the BN film to microforming die, future work should be done to decrease the wear rate of the film. As is known to all, the cubic boron nitride film has high hardness and low wear rate, if the hBN film contains some cubic structure, the wear resistance of the coating system could be improved. On the other hands, some other substrate material like WC should be used, as this material is a common material for tool application.

\section{Conclusion}

The BN film was deposited by hot filament CVD. The filament temperature influenced the decomposition rate of single source precursor and lead to different film's elemental composition and structure. The film deposited under lower filament temperature was amorphous, hBN film was deposited under higher filament temperature, and the crystallization degree of the film was improved at the higher filament temperature. The hBN film shows the lower and stable friction coefficient at the initial stage, moreover, there was no titanium adhesion on the film after ball on disk test when the film was remained. It was expected that the $\mathrm{hBN}$ film could be used for microforming die to prevent pure titanium adhesion on the tool surface.

\section{References}

1. P.B. Mirkarimi, K.F. McCarty, D.L. Medlin, Review of advances in cubic boron nitride film synthesis, Materials Science and Engineering R21 (1997) 47-100.

2. S. Logothetidis, C. Charitidis, P. Patsalas, T. Kehagias, A comparative study of composition, structure and elastic properties of boron nitride films deposited by magnetron and ion beam sputtering, Diamond and Related Materials 8 (1999) $410-414$.

3. J.X. Deng, B. Wang, L.W. Tan, H. Yan, G.H. Chen, The growth of cubic boron nitride films by RF reactive sputter, Thin Solid Films 368 (2000) 312-314.

4. G. Schwarz, F. Friess, G.K. Wolf, Deposition of c-BN by ion beam assisted CVD, Surface and Coatings Technology 125 (2000) 106-110.

5. R. Weissenbacher, R. Haubner, HF-CVD of B,C,N containing layers on various substrates by the decomposition of Triethylborazine, Diamond and Related Materials 12 (2003) 884-890.

6. H. Dumont, B. Bayle, B. Bonnetot, J. Bouix, Deposition and characterization of $\mathrm{BN} / \mathrm{Si} \quad\left(\begin{array}{lll}0 & 0 & 1\end{array}\right)$ using tris(dimethylamino)borane, Materials Research Bulletin 37 (2002) $1565-1572$.

7. J. Etter, Report on hertzian contact stress theory, OPTI 521, College of Optical Science, University of Arizona, Tucson, AZ, 2013.

8. M.A. Mannan, Y. Baba, N. Hirao, T. Kida, M. Nagano, H. Noguchi, Hexagonal nano-crystalline BCN films grown on $\mathrm{Si}(100)$ substrate studied by X-ray absorption spectroscopy, Materials Sciences and Application 4 (2013) 11-19.

9. Information on http://en.wikipedia.org/wiki/Bragg's_law

Cite this article as: Jin Y, Yasuhara S, Shimizu T \& Yang M: The influences of filament temperature on the structure of boron nitride films and its tribological characterization for microforming die application. Manufacturing Rev. 2015, 2, 4. 